\title{
Mycobacterial Cervical Lymphadenitis
}

\author{
Yıldırım A. Bayazıt ${ }^{a}$ Nurhayat Bayazıt ${ }^{b}$ Mustafa Namiduru ${ }^{b}$ \\ aDepartment of Otolaryngology, Faculty of Medicine, Gazi University, Besevler, Ankara, bDepartment of Infectious \\ Diseases and Clinical Microbiology, Faculty of Medicine, University of Gaziantep, Gaziantep, Turkey
}

\section{Key Words}

Mycobacterium tuberculosis · Atypical mycobacteria • Lymphadenitis

\begin{abstract}
Cervical lymphadenitis is the most common head and neck manifestation of mycobacterial infections. The incidence of mycobacterial cervical lymphadenitis has increased. It may be the manifestation of a systemic tuberculous disease or a unique clinical entity localized to neck. It remains a diagnostic and therapeutic challenge because it mimics other pathologic processes and yields inconsistent physical and laboratory findings. A high index of suspicion is needed for the diagnosis of mycobacterial cervical lymphadenitis. A unilateral single or multiple painless lump, mostly located in posterior cervical or supraclavicular region can occur. A thorough history and physical examination, tuberculin test, staining for acid-fast bacilli, radiologic examination, fine-needle aspiration and PCR will be instrumental in arriving at an early diagnosis early institution of treatment before a final diagnosis can be made by biopsy and culture. It is important to differentiate tuberculous from nontuberculous mycobacterial cervical lymphadenitis because their treatment protocols are different. Tuberculous adenitis is best treated as a systemic disease with antituberculosis medication. Atypical infections can be addressed as local infections and are amenable to surgical therapy.

Copyright ( 2004 S. Karger AG, Basel
\end{abstract}

\section{Introduction}

The term acid-fast bacilli is practically synonymous with mycobacteria. Mycobacterial species with similar bacteriologic features and DNA are referred to as 'complex', like $M$. tuberculosis complex and M. avium complex. The former includes $M$. tuberculosis, $M$. bovis, $M$. africanum, M. microti, $M$. ulcerans and Bacille CalmetteGuérin (BCG). Mycobacteria that are not classified as $M$. tuberculosis complex are referred to as nontuberculous mycobacteria (NTM) or atypical mycobacteria.

The tuberculous bacilli that cause disease in humans are usually $M$. tuberculosis, $M$. bovis and $M$. africanum. The latter two mostly cause extrapulmonary tuberculosis. Humans are the only reservoir for $M$. tuberculosis. In general, mycobacterial infections are grouped into infections caused by $M$. tuberculosis and those caused by the atypical mycobacterial organisms [1].

Primary infections mostly occur by contamination through the respiratory tract. Reinfection can occur any time after the primary infection either through reactivation of the endogenous source of primary infection, or contamination by an exogenous source. Miliary tuberculosis occurs when a caseating focus drains into a vessel and disseminates into the circulation. The age distribution reflects the degree of ongoing transmission in a given population. Disease in the elderly is generally due to reactivation of infection acquired in the remote past, whereas tuberculosis in young children indicates ongoing active transmission in the community.

\begin{tabular}{ll}
\hline KARGER & ( ) 2004 S. Karger AG, Basel \\
0301-1569/04/0665-0275\$21.00/0 \\
$\begin{array}{l}\text { Fax+4161306 1234 } \\
\begin{array}{l}\text { E-Mail karger@karger.ch } \\
\text { www.karger.com }\end{array}\end{array}$ & $\begin{array}{l}\text { Accessible online at: } \\
\text { www.karger.com/orl }\end{array}$
\end{tabular}

Yildırım A. Bayazıt, MD

Department of Otolaryngology

Faculty of Medicine, Gazi University

TR-06510 Besevler, Ankara (Turkey)

Tel. +90 312 2844478, Fax +90 312 2230528, E-Mail bayazity@yahoo.com 
Table 1. Clinical clues to differentiate between tuberculous and nontuberculous cervical adenitis

\begin{tabular}{|c|c|c|}
\hline Parameter & Tuberculous & Nontuberculous \\
\hline Cervical lymphadenitis & $\begin{array}{l}\text { Posterior, supraclavicular, } \\
\text { multiple, bilateral }\end{array}$ & $\begin{array}{l}\text { Enlarging mass } \\
\text { around the mandible }\end{array}$ \\
\hline $\begin{array}{l}\text { Constitutional symptoms } \\
\text { (fever, weight loss, fatigue) }\end{array}$ & Present & Absent \\
\hline $\begin{array}{l}\text { History of tuberculosis or } \\
\text { tuberculous contact }\end{array}$ & Present & Absent \\
\hline Fistula formation & High & Low \\
\hline Age & Adulthood & Childhood \\
\hline PPD & Usually positive & Intermediate, negative \\
\hline Chest X-ray & $\begin{array}{l}\text { Signs of active or previous } \\
\text { tuberculous infection }\end{array}$ & Normal \\
\hline
\end{tabular}

Cervical lymphadenitis is the most common manifestation of mycobacterial infections encountered in the otolaryngologic practice. The incidence of mycobacterial cervical lymphadenitis has increased in parallel with the increase in the incidence of mycobacterial infection worldwide. Mycobacterial cervical lymphadenitis, which is also referred to as scrofula, may be manifestation of a systemic tuberculous disease or a unique clinical entity localized to neck. It can result from direct extension or hematogenous spread of the infection [2]. Mycobacterial cervical lymphadenitis remains a diagnostic and therapeutic challenge because it mimics other pathologic processes and yields inconsistent physical and laboratory findings [3].

\section{Clinical Presentation}

Mycobacterial infection should be considered in the differential diagnosis of a cervical mass, especially in endemic areas. Lymphadenitis is the most common clinical presentation of extrapulmonary tuberculosis [4]. It may present as a unilateral single or multiple painless lump, mostly located in the posterior cervical or supraclavicular region $[2,5]$. There is a history of tuberculous contact in $21.8 \%$, and tuberculous infection in $16.1 \%$ of the cases [2]. Fistula formation can be seen in almost $10 \%$ of the mycobacterial cervical lymphadenitis [2, 6], though it is rare in atypical cases [7].

Cervical adenitis due to NTM is primarily a disease of childhood, and usually presents as a unilateral mass or draining sinus $[8,9]$. Cervical nodes in the submandibular region are most commonly affected in children $[10,11]$. Children below 3 significantly more often present with only one lesion and the referring physician more frequent- ly suspects a neoplasm, bacterial adenitis or reactive adenopathy rather than nontuberculous mycobacterial cervical lymphadenitis [12]. The portal of entry for NTM may be the oral mucosa or gingiva [13]. This is particularly important in children, because deciduous teeth may harbor the NTM that may reach the neck sites around the mandible through the lymphatics [2].

\section{Diagnosis}

A high index of suspicion is needed for the diagnosis of mycobacterial cervical lymphadenitis, which remains a diagnostic challenge for many clinicians despite current advances in diagnostic laboratory techniques.

A thorough history and physical examination, tuberculin test, staining for acid-fast bacilli , radiologic examination, and fine-needle aspiration (FNA) will help to arrive at an early diagnosis of mycobacterial cervical lymphadenitis which will allow early institution of treatment before a final diagnosis can be made by biopsy and culture [14, $15]$.

It is also important to differentiate tuberculous from nontuberculous mycobacterial cervical lymphadenitis because their treatment protocols are different. Although it is difficult to clinically differentiate tuberculous from nontuberculous lymphadenitis [16], there are some clues that may be used in their differentiation (table 1).

\section{Smears}

Smears can be obtained either from a draining sinus or by FNA. Ziehl-Neelsen staining of the smears may reveal mycobacteria in the fresh specimens; and 10,000 cells are needed for smear positivity. 
FNA cytology is useful in the diagnosis of tuberculous and nontuberculous adenitis [16-18]. It can detect cervical tuberculous lymphadenitis in $25-77 \%$ [19-22]. In NTM, acid- and alcohol-fast bacilli can be identified in $52.9 \%$ [23]. The sensitivity and specificity of FNA cytology in the diagnosis of tuberculous lymphadenitis are $88 \%$ and 96\%, respectively [16]. Combination of FNA with culture or a Mantoux test further increases the diagnostic yield in mycobacterial cervical lymphadenitis $[22,24$, 25].

FNA biopsy is a sensitive, specific and cost-effective way to diagnose mycobacterial cervical lymphadenitis [20], especially in children presenting with a suspicious neck mass [26].

\section{Culture}

Culture of mycobacterium is diagnostic for mycobacterial cervical lymphadenitis. However, a negative culture result should not exclude the diagnosis of mycobacterial cervical lymphadenitis[27]. The presence of 10-100 bacilli per cubic millimeter of the specimen is enough for a positive culture result. Different media can be used to culture the mycobateria (L-J, Petregnani, Trudeau, Middlebrook, Bactec TB). However, several weeks are needed to obtain the culture result, which may prolong the initiation of treatment.

Cultures are positive in $10-69 \%$ of the cases [2, 19, 28]. Mycobacterial cervical lymphadenitis is caused by tuberculous mycobacteria in $64 \%$ and nontuberculous mycobacteria in $36 \%$ of the cases [2]. In tuberculous adenitis, M. tuberculosis is the most common causative agent (cultured in 50\%), followed by M. bovis [14, 28]. In nontuberculous adenitis, $M$. avium-intracellulare complex is the most common causative agent [11, 24, 29, 30], and can be cultured in $68.8 \%$ of the cases [23]. It is a common causative agent of mycobacterial cervical lymphadenitis in children less than 3 years [31]. M. kansasii and M. fortuitum are rare causes [28].

\section{Tuberculin Test}

This intradermal test (Mantoux test) is used to show delayed-type hypersensitivity reactions against mycobacterial antigen, in which the reagent is mostly protein purified derivative (PPD). The test becomes positive 2-10 weeks after the mycobacterial infection. Positive reactions ( $>10-\mathrm{mm}$ induration) can occur in $M$. tuberculosis infections. Ninety percent of persons with $10-\mathrm{mm}$ and all with $>15-\mathrm{mm}$ of indurations are infected with $M$. tuberculosis. Suspicious reactions (5- to 9-mm induration) can occur after BCG vaccination, M. tuberculosis infection or nontuberculous mycobacterial infections. Negative reactions $(<4-\mathrm{mm}$ induration) represent a lack of tuberculin sensitization. False-negative reactions can occur in at least $20 \%$ of all persons with active tuberculosis. The test may also be false positive in different conditions, like other infections, metabolic disease, malnutrition, live virus vaccination, malignancy, immunosuppressive drugs, newborns, elderly people, stress, sarcoidosis and inadequate test application.

The tuberculin test is considered the principal diagnostic tool in mycobacterial infections [32, 33], though its value is debated $[22,23]$. Children with atypical mycobacterial adenitis have a decreasing tuberculin response to repeated testing, while children with tuberculous adenitis have a stable response [34]. In mycobacterial cervical lymphadenitis cases the test may be positive (49.4\%), intermediate $(35.6 \%)$ or negative $(15 \%)$ [2]. Positive results could be obtained in the majority of tuberculous infections whereas the result is mostly negative or intermediate in nontuberculous infections.

\section{Molecular Testing}

PCR testing, especially IS6110 profile, is a fast and useful technique for the demonstration of mycobacterial DNA fragments in patients with clinically suspected mycobacterial cervical lymphadenitis $[35,36]$. The presence of 10 microorganisms is enough for PCR positivity. PCR can be applied on the materials obtained by FNA or biopsy, and can reduce the necessity for open biopsy [37, 38]. Its sensitivity ranges between 43 and $84 \%$, and its specificity between 75 and $100 \%[36,39]$. PCR can be applied when smears and cultures are negative [40].

PCR is a confirmatory and sensitive technique for the diagnosis of mycobacterial cervical lymphadenitis. However, different PCR results can be obtained in different laboratories. Therefore, PCR is used as an adjunct to conventional techniques in the diagnosis of mycobacterial infections [39, 38].

\section{Histopathology}

Histopathologic examination is one of the most important means for diagnosing mycobacterial cervical lymphadenitis [3, 29, 41-43]. Langerhans giant cells, caseating necrosis, granulomatous inflammation and calcification can be seen [44]. The presence of microabscesses, illdefined granulomas, noncaseating granulomas and a small number of giant cells is more prominent in nontuberculous adenitis when compared with tuberculous adenitis $[9,23,45]$. 


\section{Radiology}

Chest roentgenogram, and ultrasound, CT and MRI of the neck can be performed in mycobacterial cervical lymphadenitis. Chest X-ray may reveal findings consistent with tuberculosis in $14-20 \%$ of the cases $[2,3,14]$. The majority of them are tuberculous infections. Chest X-ray is usually clear in nontuberculous infections [23]. Ultrasound of the neck can demonstrate singular or multiple hypoechoic and multiloculated cystic lesions that are surrounded with a thick capsule.

On CT, the presence of conglomerated nodal masses with central lucency, a thick irregular rim of contrast enhancement and inner nodularity, a varying degree of homogeneous enhancement in smaller nodes, dermal and subcutaneous manifestations of inflammation, such as thickening of the overlying skin, engorgement of the lymphatics and thickening of the adjacent muscles, and a diffusely effaced fascial plane may suggest mycobacterial cervical lymphadenitis [46, 47]. However, these findings may also be seen in other diseases like lymphoma and metastatic lymphadenopathy [46]. With gadolinium enhancement, there will be opacification around the hypodense cystic lesions.

MRI may reveal discrete, matted and confluent masses. Necrotic foci, when present, are more frequently peripheral rather than central, and this together with the soft tissue edema may be of value in differentiating mycobacterial cervical lymphadenitis from metastatic nodes [48]. If the cervical mass is necrotic, there will be low and high signal intensity in the center of the mass in $T_{1-}$ and $\mathrm{T}_{2}$-weighted images, respectively.

\section{Treatment}

It is important to distinguish between tuberculous and nontuberculous cervical lymphadenitis because the medical and surgical treatments of these entities differ [49, 50]. A tuberculous infection usually responds very well to antituberculous chemotherapy, whereas a nontuberculous mycobacterial infection may require a surgical intervention [51, 52].

Tuberculous adenitis responds well to antituberculous drugs, and surgery has a limited role in the treatment. A surgical intervention in tuberculous adenitis should include FNA, drainage, and incisional or limited excisional biopsy [53].

In nontuberculous adenitis, surgery is the treatment of choice: it provides a rapid tissue diagnosis and confirms the bacterial type $[54,55]$. Surgery increases the cure rate with excellent cosmetic result and a low complication rate [56]. Antibiotics are used to augment surgical therapy [15].

Surgical techniques include aspiration, incision and drainage, curettage, complete surgical excision of the affected lymph nodes and the overlying skin, and selective nodal or functional neck dissection when required. Briefly, the treatment of choice is complete surgical excision of all affected tissue [11]. Aspiration, which may result in $50 \%$ cure rate, can be performed when surgical excision is limited because of the proximity of adenitis to the facial nerve or its branch [57]. Curettage, which may result in $70 \%$ cure rate, can also be made when the lesion is in proximity to the nerve or there is extensive skin necrosis $[17,58]$. Simple incision and drainage are associated with prolonged postoperative wound discharge and hypertrophic scarring [59]. Total excision is made for a singular lump while selective nodal or functional neck dissection for multiple lumps. In nontuberculous adenitis, the recurrence rate of complete surgical resection is less than $1 \%$ [60]. Excision of the skin overlying the mass can be performed when there is a fistula, scar formation, or necrosis. Dilated lymphatics can be seen around the lymphadenitis during surgery, which should be secured to prevent the formation of a chylous fistula postoperatively.

Medical treatment for mycobacterial cervical lymphadenitis includes antibiotics, which are used in combinations in order to sterilize the infectious focus and to prevent the development of drug resistance. There are two groups of antituberculous drugs. First-line drugs are isoniazid (INH), rifampin (RMB), ethambutol (EMB), pyrazinamide (PZA) and streptomycin (STM). Second-line drugs, which are less efficacious and more toxic than the first-line drugs, are capreomycin, kanaycin, ethionamide, thiacetazone, para-aminosalicyclic acid and cycloserine. INH may be hepatotoxic, RMB and PZA may cause hepatorenal disorders, STM may be ototoxic and nephrotoxic. EMB may cause optic neuritis. Resistance to one or more drugs is seen in $61 \%$ of isolated strains with maximum resistance to INH and minimum to EMB [61]. Treatment should not be deferred during pregnancy. If there is a contraindication, multiple puncturing, aspiration and compressive dressing can be made until termination of the pregnancy. Otherwise, INH and EMB can be used in drug-sensitive cases. RMP can also be used when a 9month regimen is advocated. STM and PZA are not recommended during pregnancy. A biopsy can be obtained under local anesthesia during pregnancy. However, complete surgical excision under general anesthesia can be performed after the second trimester. 
There is no standard regimen for the medical treatment of mycobacterial cervical lymphadenitis. For tuberculous adenitis, there are treatment schedules of 6 and 9 months duration, which have similar relapse rates of 3.3 and $2.7 \%$, respectively [62]. In our experience, we advocate 12 and 18 months of drug treatment for tuberculous and nontuberculous mycobacterial cervical lymphadenitis, respectively, which results in complete cure after 2 years of follow-up in nearly all cases $[2,50]$. The advocated regimen is as follows; (1) STM ( $1 \mathrm{~g}, \mathrm{i} . \mathrm{m}$.) for 3 months with a total dose of not more than $45 \mathrm{~g}$. It is given as follows; every day for the first 2 weeks, every other day for 1 month, and every 3 days for 1.5 months; (2) RIF $(600 \mathrm{mg} /$ day, p.o.) for 6 months; (3) INH $(300 \mathrm{mg} / \mathrm{day}$, p.o.) for 12 or 18 months; (4) EMB (900 mg/day, p.o.) for 12 or 18 months.

\section{Conclusion}

Tuberculosis is a systemic disease, with cervical lymphadenitis of the neck being the most common extrapulmonary manifestation of the disease. Mycobacterial cervical lymphadenitis is caused either by tuberculous or nontuberculous mycobacteria. Their diagnosis and distinction need a high index of suspicion, and application of a variety of diagnostic modalities. It is not feasible or practical to apply all of the diagnostic procedures in all patients. This would be time consuming and expensive. The test battery should be individualized depending on the location of the disease and the clinical evaluation.

Tuberculous adenitis is best treated as a systemic disease with antituberculosis medication. Atypical infections can be addressed as local infections and are amenable to surgical therapy.

\section{References}

$\checkmark 1$ Munck K, Mandpe AH: Mycobacterial infections of the head and neck. Otolaryngol Clin North Am 2003;36:569-576.

-2 Kanlikama M, Mumbuç S, Bayazit Y, Sirikci A: Management strategy of mycobacterial cervical lymphadenitis. J Laryngol Otol 2000;114: 274-278.

$\checkmark 3$ Alleva M, Guida RA, Romo T 3rd, Kimmelman CP: Mycobacterial cervical lymphadenitis: A persistent diagnostic problem. Laryngoscope 1988;98:855-857.

4 Haas DW: Mycobacterium tuberculosis. Principles and practice of infectious disease; in Mandell GL, Bennett JE, Dolin R (eds): Principles and Practice of Infectious Diseases, ed 5. Philadelphia, Churchill Livingstone, 2000, pp 25762607.

$>5$ Penfold CN, Revington PJ: A review of 23 patients with tuberculosis of head and neck. $\mathrm{Br}$ J Oral Maxillofac Surg 1996;34:508-510.

6 Konishi K, Yamane H, Iguchi H, Nakagawa T, Shibata S, Takayama M, et al: Study of tuberculosis in the field of otorhinolaryngology in the past 10 years. Acta Otolaryngol Suppl 1998; 598:244-249.

$>7$ Olson NR: Atypical mycobacterial cervical lymphadenitis: Clinical presentation. Laryngoscope 1967;77:1376-1379.

$>8$ Thompson JN, Watanabe MJ, Greene GR, Morozumi PA, Kohut RI: Atypical mycobacterial cervical adenitis: Clinical presentation. Laryngoscope 1980;90:287-294.

$>9$ Kuth G, Lamprecht J, Haase G: Cervical lymphadenitis due to mycobacteria other than tuberculosis - an emerging problem in children? ORL J Otorhinolaryngol Relat Spec 1995;57: 36-38.
10 Dhooge I, Dhooge C, De Baets F, Van Cauwenberge P: Diagnostic and therapeutic management of atypical mycobacterial infections in children. Eur Arch Otorhinolaryngol 1993;250: 387-391.

11 Danielides V, Patrikakos G, Moerman M, Bonte K, Dhooge C, Vermeersch H: Diagnosis, management and surgical treatment of nontuberculous mycobacterial head and neck infection in children. ORL J Otorhinolaryngol Relat Spec 2002;64:284-289.

12 Kvaerner KJ, Kvestad E, Orth M: Surgery required to verify atypical mycobacterial infections. Int J Pediatr Otorhinolaryngol 2001;61: 121-128.

13 Olson NR: Nontuberculous mycobacterial infections of the face and neck-practical considerations. Laryngoscope 1981;91:1714-1726.

14 Ibekwe AO, al Shareef Z, al Kindy S: Diagnostic problems of tuberculous cervical adenitis (scrofula). Am J Otolaryngol 1997;18:202205.

15 Albright JT, Pransky SM: Nontuberculous mycobacterial infections of the head and neck. Pediatr Clin North Am 2003;50:503-514.

16 Chao SS, Loh KS, Tan KK, Chong SM: Tuberculous and nontuberculous cervical lymphadenitis: A clinical review. Otolaryngol Head Neck Surg 2002; 126:176-179.

17 Tunkel DE: Surgery for cervicofacial nontuberculous mycobacterial adenitis in children: An update. Arch Otolaryngol Head Neck Surg 1999; 125:1109-1113.

18 Weiler Z, Nelly P, Baruchin AM, Oren S: Diagnosis and treatment of cervical tuberculous lymphadenitis. J Oral Maxillofac Surg 2000;58: 477-481.
19 Gupta SK, Chugh TD, Sheikh ZA, al-Rubah NA: Cytodiagnosis of tuberculous lymphadenitis. A correlative study with microbiologic examination. Acta Cytol 1993;37:329-332.

20 Lau SK, Wei WI, Hsu C, Engzell UC: Fine needle aspiration biopsy of tuberculous cervical lymphadenopathy. Aust N Z J Surg 1988;58: 947-950.

21 Bezabih M, Mariam DW, Selassie SG: Fine needle aspiration cytology of suspected tuberculous lymphadenitis. Cytopathology 2002;13: 284-290.

22 Lau SK, Wei WI, Kwan S, Yew WW: Combined use of fine-needle aspiration cytologic examination and tuberculin skin test in the diagnosis of cervical tuberculous lymphadenitis. A prospective study. Arch Otolaryngol Head Neck Surg 1991;117:87-90.

23 Evans MJ, Smith NM, Thornton CM, Youngson GG, Gray ES: Atypical mycobacterial lymphadenitis in childhood - a clinicopathological study of 17 cases. J Clin Pathol 1998;51:925927.

24 Tunkel DE, Romaneschi KB: Surgical treatment of cervicofacial nontuberculous mycobacterial adenitis in children. Laryngoscope 1995; 105:1024-1028.

25 Ellison E, Lapuerta P, Martin SE: Fine needle aspiration diagnosis of mycobacterial lymphadenitis. Sensitivity and predictive value in the United States. Acta Cytol 1999;43:153157.

26 Liu ES, Bernstein JM, Sculerati N, Wu HC: Fine needle aspiration biopsy of pediatric head and neck masses. Int J Pediatr Otorhinolaryngol 2001;60:135-140. 
27 Jackson DP, Hayden JD, Quirke P: Extraction of nucleic acids from fresh and archival material. PCR A Practical Approach; in McPherson MJ, Quirke P, Taylor GR (eds). Oxford, IRL Press, 1991, pp 29-49.

-28 Kanlikama M, Ozsahinoglu C, Akan E, Ozcan $\mathrm{K}$ : Mycobacterial species causing cervicofacial infection in Turkey. Eur Arch Otorhinolaryngol 1993;250:237-239.

-29 Flint D, Mahadevan M, Barber C, Grayson D, Small R: Cervical lymphadenitis due to nontuberculous mycobacteria: Surgical treatment and review. Int $\mathrm{J}$ Pediatr Otorhinolaryngol 2000;53:187-194.

30 Maltezou HC, Spyridis P, Kafetzis DA: Nontuberculous mycobacterial lymphadenitis in children. Pediatr Infect Dis J 1999; 18:968-970.

-31 Spark RP, Fried ML, Bean CK, Figueroa JM, Crowe CP Jr, Campbell DP: Nontuberculous mycobacterial adenitis of childhood. The tenyear experience at a community hospital. Am J Dis Child 1988;142:106-108.

- 32 Saggese D, Compadretti GC, Burnelli R: Nontuberculous mycobacterial adenitis in children diagnostic and therapeutic management. Am J Otolaryngol 2003;24:79-84.

-33 Cinar F, Cinar S, Yilmaz B, Gursel O: Purified protein derivative: The vital part of the cervical tuberculous adenitis diagnosis. Otolaryngol Head Neck Surg 2003;129:245-247.

34 Schuit KE, Powell DA: Mycobacterial lymphadenitis in childhood. Am J Dis Child 1978; 132:675-677.

\35 April MM, Garelick JM, Nuovo GJ: Reverse transcriptase in situ polymerase chain reaction in atypical mycobacterial adenitis. Arch Otolaryngol Head Neck Surg 1996;122:1214-1218.

36 Manitchotpisit B, Kunachak S, Kulapraditharom B, Sura T: Combined use of fine needle aspiration cytology and polymerase chain reaction in the diagnosis of cervical tuberculous lymphadenitis. J Med Assoc Thai 1999;82: 363-368.

-37 Baek CH, Kim SI, Ko YH, Chu KC: Polymerase chain reaction detection of Mycobacterium tuberculosis from fine-needle aspirate for the diagnosis of cervical tuberculous lymphadenitis. Laryngoscope 2000;110:30-34.
38 Singh KK, Muralidhar M, Kumar A, Chattopadhyaya TK, Kapila K, Singh MK, Sharma SK, Jain NK, Tyagi JS: Comparison of in house polymerase chain reaction with conventional techniques for the detection of Mycobacterium tuberculosis DNA in granulomatous lymphadenopathy. J Clin Pathol 2000;53:355-361.

39 Hirunwiwatkul P, Tumwasorn S, Chantranuwat C, Sirichai U: A comparative study of diagnostic tests for tuberculous lymphadenitis: Polymerase chain reaction vs. histopathology and clinical diagnosis. J Med Assoc Thai 2002; 85:320-326.

40 Kwon KS, Oh CK, Jang HS, Lee CW, Jun ES: Detection of mycobacterial DNA in cervical granulomatous lymphadenopathy from formalin-fixed, paraffin-embedded tissue by PCR. J Dermatol 2000;27:355-360.

41 Shikhani AH, Hadi UM, Mufarrij AA, Zaytoun GM: Mycobacterial cervical lymphadenitis.Ear Nose Throat J 1989;68:668-672.

42 Manolidis S, Frenkiel S, Yoskovitch A, Black M: Mycobacterial infections of the head and neck. Otolaryngol Head Neck Surg 1993;109: 427-433.

43 Artenstein AW, Kim JH, Williams WJ, Chung RC: Isolated peripheral tuberculous lymphadenitis in adults: Current clinical and diagnostic issues. Clin Infect Dis 1995;20:876-882.

44 Suskind DL, Handler SD, Tom LW, Potsic WP, Wetmore RF: Non-tuberculous cervical lymphadenitis. Clin Pediatr 1997;36:403-409.

45 Kraus M, Benharroch D, Kaplan D, Sion-Vardy N, Leiberman A, Dima H, Shoham I, Fliss DM: Mycobacterial cervical lymphadenitis: The histological features of non-tuberculous mycobacterial infection. Histopathology 1999; 35:534-538.

46 Kim YJ, Sung KJ, Kim MS, Hong IS: CT manifestations of cervical tuberculous lymphadenitis. J Otolaryngol 1993;22:321-325.

47 Nadel DM, Bilaniuk L, Handler SD: Imaging of granulomatous neck masses in children. Int J Pediatr Otorhinolaryngol 1996;37:151-162.

48 King AD, Ahuja AT, Metreweli C: MRI of tuberculous cervical lymphadenopathy. J Comput Assist Tomogr 1999;23:244-247.

49 Domb GH, Chole RA: The diagnosis and treatment of scrofula (mycobacterial cervical lymphadenitis). Otolaryngol Head Neck Surg 1980;88:339-341.
50 Kanlikama M, Gokalp A: Management of mycobacterial cervical lymphadenitis. World J Surg 1997;21:516-519.

51 Appling D, Miller RH: Mycobacterium cervical lymphadenopathy: 1981 update. Laryngoscope 1981;91:1259-1266.

52 White MP, Bangash H, Goel K, Jenkins PA: Non-tuberculous mycobacterial lymphadenitis. Arch Dis Chil 1983;84:368-372.

53 Ammari FF, Bani Hani AH, Ghariebeh KI: Tuberculosis of the lymph glands of the neck: A limited role for surgery. Otolaryngol Head Neck Surg 2003;128:576-580.

54 Castro DJ, Hoover L, Castro DJ, Zuckerbraun L: Cervical mycobacterial lymphadenitis. Medical vs surgical management. Arch Otolaryngol 1985;111:816-819.

55 Stewart MG, Starke JR, Coker NJ: Nontuberculous mycobacterial infections of the head and neck. Arch Otolaryngol Head Neck Surg 1994;120:873-876.

56 Rahal A, Abela A, Arcand PH, Quintal MC, Lebel MH, Tapiero BF: Nontuberculous mycobacterial adenitis of the head and neck in children: Experience from a tertiary care pediatric center. Laryngoscope 2001;111:1791-1796.

57 Alessi DP, Dudley JP: Atypical mycobacteriainduced cervical adenitis. Treatment by needle aspiration. Arch Otolaryngol Head Neck Surg 1988;114:664-666.

58 Fergusson JA, Simpson E: Surgical treatment of atypical mycobacterial cervicofacial adenitis in children. Aust N Z J Surg 1999;69:426-429.

59 Mandell DL, Wald ER, Michaels MG, Dohar JE: Management of nontuberculous mycobacterial cervical lymphadenitis. Arch Otolaryngol Head Neck Surg 2003;129:341-344.

60 Panesar J, Higgins K, Daya H, Forte V, Allen $\mathrm{U}$ : Nontuberculous mycobacterial cervical adenitis: A ten-year retrospective review. Laryngoscope 2003;113:149-154.

61 Nataraj G, Kurup S, Pandit A, Mehta P: Correlation of fine needle aspiration cytology, smear and culture in tuberculous lymphadenitis: A prospective study. J Postgrad Med 2002;48: 113-116.

62 van Loenhout-Rooyackers JH, Laheij RJ, Richter C, Verbeek AL: Shortening the duration of treatment for cervical tuberculous lymphadenitis. Eur Respir J 2000;1 5:192-195 